SURGERY

Mytsyk Yu.O., Borys Yu.B., Dutka I.Yu., Datz I.V., Motrynets N.P., Kucher A.R., Pasichnyk S.M., Borys B.Yu., Mytsyk O.I., Matskevych V.M..

\title{
APPLICATION OF THE DIFFUSION-WEIGHTED MRI FOR PREDICTION OF THE INTRAOPERATIVE BLOOD LOSS DURING THE NEPHRECTOMY IN PATIENTS WITH RENAL CELL CARCINOMA AFTER EMBOLIZATION OF RENAL ARTERY
}

Danylo Halytsky Lviv National Medical University, Ukraine

\begin{abstract}
During the last decade renal artery embolization (RAE) is used for preparation of patients with renal cell carcinoma (RCC) of large size or significant vascularization to surgical treatment. Currently there is no accurate method of prediction of intraoperative blood loss in patients with RCC after RAE, that may give possibility for more adequate pre- and postoperative patient management and to define the indications for re-embolization. Goal. The goal of the study was to evaluate the possibility of application of diffusionweighted imaging (DWI) of MRI and of apparent diffusion coefficient (ADC) for the prediction of the estimated intraoperative blood loss (EIBL) during the open radical nephrectomy in patients with RCC and after RAE. Materials and methods. The study enrolled 33 patients (main group, 18 males and 15 females) with solid RCC according to clinical and radiologic data and with the indications to selective RAE with subsequent radical nephrectomy. Mean size of the tumor was $8.6 \pm 3.8 \mathrm{~cm}$ in greatest dimension. In all patients with RCC in the same day or day before RAE and 7 days after the RAE MRI with additional DWI sequence with $b$-value $=0.800$ was performed. Subsequent measuring of the $A D C$ over the tumor region was done in all cases. $A D C$ values of the normal renal parenchyma for control were achieved during the examination of 15 healthy volunteers. In all patients with RCC 7-8 days after the RAE open radical nephrectomy with simultaneous EIBL measurement was executed. Results. In patients with EIBL less than $500 \mathrm{ml}$ and with no episodes of the hemotransfusions mean $A D C$ value decreased by $18.4-31.9 \%$ in comparison with initial $A D C$ value. As opposed to that in patients with EIBL more than $500 \mathrm{ml}$ and in selected cases with hemotransfusions mean ADC value increased by $4.91-65.64 \%$ compared to baseline value. Analysis of the acquired data showed significant $(\mathrm{p}<0.05)$ difference in main group of patients in whom no hemotransfusions were required in post-op period $(\mathrm{n}=27,81.82 \%)$ in mean $A D C$ values before and after RAE (decrease by $20.25 \%): 1.63 \pm 0.31 \times 10-3 \mathrm{~mm} 2 / \mathrm{s}$ vs $1.30 \pm 0.19 \times 10-3 \mathrm{~mm} 2 / \mathrm{s}$. In main group patients with hemotransfusions in post-op period this value increased by $28.83 \%: 1.63 \pm 0.31 \times 10-3$ $\mathrm{mm} 2 / \mathrm{s}$ vs $2.10 \pm 0.47 \times 10-3 \mathrm{~mm} 2 / \mathrm{s}(p<0.05)$. Conclusions. In the result of our study strong direct relationship (correlation coefficient $r=0,96)$ between the volume of EIBL during open radical nephrectomy and ADC values in patients with RCC after RAE was detected. Application of MRI and its imaging biomarkers may be valuable clinical instrument for the prediction of the EIBL volume during the open radical nephrectomy in patients with RCC after RAE and need of the hemotransfusion in post-op period.
\end{abstract}

KeyWords: renal cell carcinoma, embolization, biomarker, nephrectomy, blood loss, MRI.

\section{INTRODUCTION}

Renal cell carcinoma (RCC) accounts for approximately $3.7 \%$ of all adult malignancies and more than 90 $\%$ of neoplasm arising from kidney. According to $\mathrm{Na}$ tional Cancer Registry of Ukraine during last years the indices of morbidity and mortality continued at a stable high level with a tendency to growth.

\section{Corresponding Author:}

Mytsyk Yu.O., MD, PhD, Danylo Halytsky Lviv National Medical University, Department of Urology, Lviv, Ukraine. E-mail:

mytsyk.yulian@i.ua
In 2014 in Ukraine the indices of morbidity and mortality after RCC accounts for 11.3 ( 14 men and 9 women) and 5.3 (7.5 men and 3.4 women) and in 201511.7 (15.0 men and 8.8 women) та 5.1 (7.3 men and 3.2 women) per 100 thousand of population accordingly [1].

The «gold standard» for localized and locally advanced RCC treatment is nephrectomy in despite of new alternative methods. During the last decade renal artery embolization (RAE) is used as preparation of patients with big or/and hypervascularized RCC's for surgical treatment [2]. The main advantages of RAE before nephrectomy are: re- 
duction of tumor clots 'size (that facilitate its removal), blood loss reduction during surgery, alleviation of dissection because of edema development. RAE is usually performed 7-10 days before surgery.

The adverse side of RAE is postinfarction syndrome, which appear as pain in the iliac region, nausea and fever, this syndrome occur in $3 / 4$ of patients. Some authors observe significant blood loss during nephrectomy after RAE, perhaps it is caused by the incomplete schematization of tumor tissues. Literature data about efficiency of RAE performed as preparation of patients with RCC to nephrectomy are often contradictory, especially concerning estimated intraoperative blood loss (EIBL) volume and amount of blood transfusion, operative time, complications and survival rates $[7,13]$. Thus, according to Schwartz and coauthors EIBL volume during radical nephrectomy in patients with RCC after RAE with median tumor size of 11.2 $\mathrm{cm}$ was variable and ranged from 100 to $5000 \mathrm{ml}$ [11]. In another new research conducted by Ramaswamy, was established, that blood transfusion volume after radical nephrectomy in patients with RCC after total RAE also was also significantly variable and ranged from 222 to $1050 \mathrm{ml}$ [10]. At the same time, according to Suad and co-authors, medium volumes of EIBL and intraoperative blood transfusion amounted $300 \mathrm{ml}$ and $250 \mathrm{ml}$ accordingly [5].

Currently there is no accurate method of prediction of EIBL volume during nephrectomy in patients with RCC after RAE, that may give possibility for more adequate treatment planning and postoperative patient management and to define the indications for re-embolization. In the last years the attention of researchers was focused on investigation of MRI and its modalities as diffusion weighted imaging (DWI) to estimate the efficiency of arterial embolization in treatment of benign and malignant tumors, as uterine fibroid and leiomyoma, hepatocellular cancer and breast cancer [3, 6, 9, 12]. DWI is the MRI sequence, which uses strong bipolar gradients to enhance sensitivity to thermally induced Brownian motion of hydrogen molecules, that allows to measure molecular diffusion in tissues in vivo and it is important for profound characteristic of neoplasm [4]. However, all conducted studies were directed toward estimating the efficiency of arterial embolization, which was performed as a disease palliation but not during preparation to surgery.

In our previous work we investigated the efficiency of DWI MRI and its quantitative parameter - apparent diffusion coefficient $(A D C)$ as imaging biomarkers in differential diagnostic of solid and cystic RCCs, benign renal tumors, benign cysts and abscesses [8]. We achieved statistically significant difference in mean ADC values of RCC and of the healthy renal parenchyma. We observed significant restriction of diffusion of hydrogen molecules in regions of solid neoplasms and it's increase in renal cysts and in abscesses in comparison with normal kidney parenchyma. Taking into account that tissue density affects diffusion of hydrogen molecules in them and that $A D C$ consists of 3 main components - intracellular (inside the cytoplasm), extracellular (in the interstitial liquid, in blood and lymph vessels) and diffusion between intra- and extracellular enviroments, we suggested that DWI and $A D C$ may be used as imaging biomarkers for evaluation of changes, which occurs in RCC tissues after RAE and for prediction of intraoperative blood volume loss in patients in whom nephrectomy will be executed.

\section{PURPOSES, SUBJECTS and METHODS:}

2.1 Purpose The goal of the study was to evaluate the possibility of application of DWI of MRI and of ADC for prediction of the EIBL during the open radical nephrectomy in patients with RCC and after RAE.

\subsection{Subjects \& Methods}

The study was allowed by Ethics Committee and conducted on the basis of the Departments of Urology and Radiology of Danylo Halytsky Lviv National Medical University, Department of Interventional Radiology of Lviv Emergency Hospital, Center of Endourology of Lviv Clinical Railway Hospital and at the Medical Center "Euroclinic", Lviv, during 2013-2017 years.

The main group enrolled 33 patients ( 18 males and 15 females) with solid RCC according to clinical and radiologi- 
swabs from the same lot were subtracted; during weighing capacities for blood the mass of blank capacities were subtracted; blood volume, which got on surgical sheet, under body of the patient was assessed; the volume of the solution for irrigation was taken into account and it was subtracted from the general volume of EIBL.

Control MRI was performed in all patients 7 days after nephrectomy, which on purpose to reduce financial and temporal expense, included only 2 sequences: coronal T2weighted single shot fast spin echo (SSFSE) and DWI with identical to above mentioned parameters. The mean duration of the examination was 10 minutes.

$A D C$ was measured using $A D C$-maps, which were generated automatically on the workstation based on DWI and which were used for assessment of diffusion in RCC tissues before and after RAE. Region of interest (ROI) was placed over the tumor region to measure the $A D C$ value whereupon it was measured (image 1).

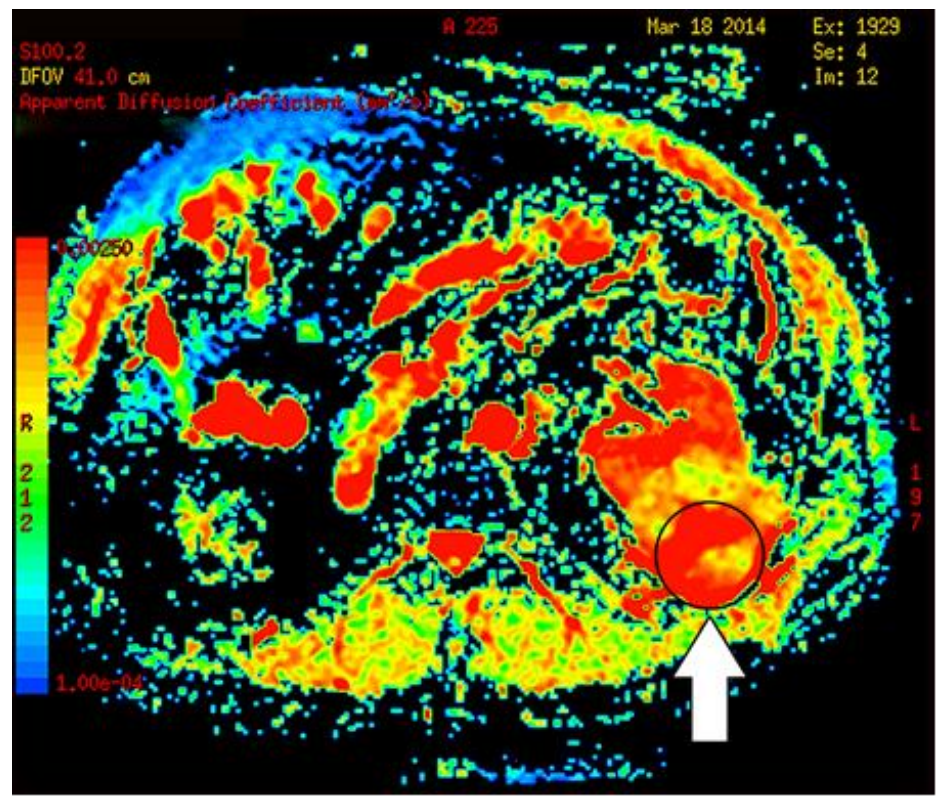

Fig. 1. ADC-map of the patient with RCC of the left kidney before RAE (pointer), ROI is placed over the tumor region, obtained $A D C$ value - 1,62 $\times 10-3 \mathrm{~mm} 2 / \mathrm{s}$.

We obtained $A D C$ values of the healthy renal parenchyma in 15 healthy volunteers without renal pathology (control group) according to data of clinical and imaging research ( 9 males and 6 females), aged from 38 to 50 years old (with median age 48,2 $\pm 1,8$ years). For assessment of morpho-functional status of kidneys all volunteers passed 
through appropriate examination before been included into research: general analysis of blood and urine, biochemical analysis of blood (creatinine, urea, ALT, AST), renal US. MRI was done to all volunteers using 2 sequences: coronal T2weighted SSFSE and DWI with analogical to the main group parameters. For measurement of $A D C$ values, ROI with median diameter of $3,5 \mathrm{~cm}$ was located over renal parenchyma and then registration was performed according to technique described earlier [8].

Antitumor therapy wasn't performed before MRI, RAE and surgery. People with metallic details inside the body weren't included in the study.

Statistics. Microsoft Exel 2016 was used for statistical analysis of obtained data, by Student-Fisher's method and for calculation of Pearson correlation coefficient. Value $p<0.05$ considered as a statistically significant result.

\section{Conflict of interests}

There is no conflict of interests.

\section{RESULTS AND DISCUSSION}

During the open nephrectomy in patients with RCC after RAE, EIBL varied from 158 to $1250 \mathrm{ml}$, the mean volume was $457,3 \pm 260,52 \mathrm{ml}$. Depending on the EIBL all patients of the main group were separated into 4 different categories: I category- EIBL - 0-250 ml ( $n=9,27,27 \%)$, II category - EIBL 250-500 ml ( $n=14,42,42 \%)$, III category EIBL 500-1000 ml ( $n=8,24,24 \%)$ and IV category - EIBL more than $1000 \mathrm{ml}(\mathrm{n}=2,6,06 \%)$. Medium values of EIBL for each category were: I - 216,55 $\pm 34,45 \mathrm{ml}$, II - 387,29 $\pm 64,19 \mathrm{ml}$,

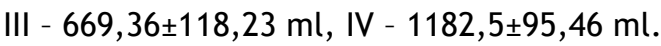

We established, that medium $A D C$ value of the healthy renal parenchyma of volunteers was $2,47 \pm 0,12 \times 10-3$ $\mathrm{mm} 2 / \mathrm{s}$. In a result of analysis of the obtained ADC data we obtained statistically significant $(p<0.05)$ difference between the mean $A D C$ values in the main group before and after RAE and in control group: $1,63 \pm 0,31 \times 10-3 \mathrm{~mm} 2 / \mathrm{s}$ vs $1,44 \pm 0,40 \times 10-3$ vs $2,47 \pm 0,12 \times 10-3 \mathrm{~mm} 2 / \mathrm{s}$ accordingly. We observed direct correlation between the values of EIBL volume and $A D C$ in patients after RAE, Pearson correlation coefficient was $r=0,96$. In patients of I and II categories with EIBL volume less than $500 \mathrm{ml}$ and with no episodes of hemotransfusions mean $A D C$ value decreased by $18.4-31.9 \%$ compared to baseline value, because of bigger infarct areas of the tumor tissues, decrease of microcirculation and as a result the restriction of hydrogen molecules diffusion. As opposed to that in patients of III and IV categories with ElBL volume more than $500 \mathrm{ml}$ and in some cases with hemotransfusions mean $A D C$ value increased by 4.91-65.64\% compared to baseline value. The interconnection between the increase of this $A D C$ value and EIBL volume in the IV category of the patients can be explained with expressed oedema of the renal tissue near infarct area, necrotic process and deficient decrease of microcirculation in tumor area. All of this together conduced the increase of molecular diffusion in tumor tissues and possibly as a result of it the increase of bleeding during surgery. The detailed description of EIBL and ADC values of the patients with RCC before and after RAE presented in table 1.

Table 1.

\section{Mean ADC values of the main group of patients before and after RAE and EIBL volume.}

\begin{tabular}{|c|c|c|c|}
\hline $\begin{array}{ll}\text { Category } & \text { of } \\
\text { patients/ } & \\
\text { subgroup } & \end{array}$ & $\begin{array}{l}\text { Mean ADC } \\
\text { before } \\
\text { RAE, } \\
\times 10^{-3} \\
\mathrm{~mm}^{2} / \mathrm{s}\end{array}$ & $\begin{array}{l}\text { Mean } \mathrm{ADC} \\
\text { after RAE, } \\
\times 10^{-3} \\
\mathrm{~mm}^{2} / \mathrm{s}\end{array}$ & $\begin{array}{l}\text { Mean EIBL, } \\
\text { (range), ml }\end{array}$ \\
\hline $\begin{array}{l}\text { Category I, } \\
\text { EIBL 0-250 ml } \\
(n=9)\end{array}$ & \multirow[t]{6}{*}{$1.63 \pm 0.31$} & $1.11 \pm 0.10$ & $\begin{array}{l}216.55 \pm 34.45 \\
(158-250)\end{array}$ \\
\hline $\begin{array}{l}\text { Category II, } \\
\text { EIBL 250-500 ml } \\
(n=14)\end{array}$ & & $1.33 \pm 0.08$ & $\begin{array}{l}387.29 \pm 64.19 \\
(275-487)\end{array}$ \\
\hline $\begin{array}{l}\text { Category III, } \\
\text { EIBL 500-1000 ml } \\
(n=8)\end{array}$ & & $1.71 \pm 0.12$ & $\begin{array}{l}669.36 \pm 118.23 \\
(510-823)\end{array}$ \\
\hline $\begin{array}{l}\text { Category IV, } \\
\text { EIBL >1000 ml } \\
(n=2)\end{array}$ & & $2.70 \pm 0.06$ & $\begin{array}{l}1182.5 \pm 95.46 \\
(1115-1250)\end{array}$ \\
\hline $\begin{array}{l}\text { Patients, in } \\
\text { whom no hemo- } \\
\text { transfusions } \\
\text { were required } \\
(\mathrm{n}=27)\end{array}$ & & $1.30 \pm 0.19^{*}$ & $\begin{array}{l}351.33 \pm 119.75 \\
(158-570)\end{array}$ \\
\hline $\begin{array}{l}\text { Patients, who } \\
\text { had hemotrans- } \\
\text { fusion } \\
(\mathrm{n}=6)\end{array}$ & & $2.10 \pm 0.47^{*}$ & $\begin{array}{l}899.0 \pm 226.45 \\
(720-1250)\end{array}$ \\
\hline
\end{tabular}

\footnotetext{
${ }^{*}$ comparison of groups between each other $(\mathrm{p}<0.05)$
} 
European Urology, 67(3), 519-530.

Analysis of the acquired data showed significant $(p<0.05)$ difference in in mean $A D C$ values in subgroup of patients in whom no hemotransfusions were required in post-op period $(\mathrm{n}=27,81.82 \%)$ in comparison with baseline mean $A D C$ value: $1.30 \pm 0.19 \times 10-3 \mathrm{~mm} 2 / \mathrm{s}$ vs $1.63 \pm 0.31 \times 10-3 \mathrm{~mm} 2 / \mathrm{s}$ accordingly (decrease by 20.25\%). In sungroup of patients with hemotransfusions in post-op period $(n=6,18,18 \%)$, the mean $A D C$ value increased by $28.83 \%$ compared to baseline value: $1.63 \pm 0.31 \times 10-3 \mathrm{~mm} 2 / \mathrm{s}$ vs $2.10 \pm 0.47 \times 10-3$ $\mathrm{mm} 2 / \mathrm{s}$, such difference was statistically significant $(p<0.05)$.

\section{CONCLUSIONS}

1. In the result of our study strong direct correlation $(r=0,96)$ was observed between the volume of EIBL during open radical nephrectomy and $A D C$ values in patients with RCC after RAE;

2. In patients of the main group that required hemotransfusions in post-op period the mean $A D C$ value increased by $28.83 \%$ compared to baseline, in patients in whom hemotransfusion wasn't performed mean $A D C$ value increased by $20.25 \%: 2.10 \pm 0.47 \times 10-3 \mathrm{~mm} 2 / \mathrm{s}$ vs $1.30 \pm 0.19 \times 10-3 \mathrm{~mm} 2 / \mathrm{s}(\mathrm{p}<0.05)$;

3. The application of MRI and its imaging biomarkers DWI and $A D C$ may be valuable clinical instrument for prediction of the EIBL volume during the open radical nephrectomy in patients with RCC after RAE and need of the hemotransfusion in postoperative period.

\section{REFERENCES}

1. Fedorenko, Z.P., Mykhaylovych, Yu.J., Hulak, L.O. (2015). Rak v Ukraini, 2014-2015. Bul. Nats. cancerrejestru Ukrainy №17, Kyiv, 56-57. (Fedorenko, Z.P., Mykhaylovych, Yu.J., Hulak, L.O. (2015) Cancer in Ukraine, 2014-2015. Bul. National cancer-register of Ukraine №17, Kyiv, 56-57).

2. Znaor, A., Lortet-Tieulent, J., Laversanne, M., Jemal, A., \& Bray, F. (2015). International variations and trends in renal cell carcinoma incidence and mortality.
3. Wein, A,J., Kavoussi, L.R., Partin, A.W. (2016). Campbell-Walsh Urology, 11th Edition. Elsevier, 14141416.

4. Duan, X.-H., Li, Y.-S., Han, X.-W., Wang, Y.-L., Jiao, D.C., Li, T.-F., ... Fang, Y. (2016). C-arm CT-guided renal arterial embolisation followed by radiofrequency ablation for treatment of patients with unresectable renal cell carcinoma. Clinical Radiology, 71(1), 79-85.

5. Bigot, P., Bouvier, A., Panayotopoulos, P., Aubé, C., \& Azzouzi, A. R. (2016). Partial nephrectomy after selective embolization of tumor vessels in a hybrid operating room: A new approach of zero ischemia in renal surgery. Journal of Surgical Oncology, 113(2), 135137.

6. Muller, A., \& Rouvière, O. (2015). Renal artery embolization-indications, technical approaches and outcomes. Nature Reviews Nephrology, 11(5), 288-301.

7. Zelens'kyı̆, R. O. (2015). Evaluation of vascular bed before and after embolization of renal artery for renal cancer. Klinichna Khirurhiia, (1), 32-34.

8. Reinhart, H. A., Ghaleb, M., \& Davis, B. R. (2015). Transarterial embolization of renal tumors improves surgical outcomes: A case series. International Journal of Surgery Case Reports, 15, 116-118.

9. Schwartz, M. J., Smith, E. B., Trost, D. W., \& Vaughan, E. D. (2007). Renal artery embolization: clinical indications and experience from over 100 cases. BJU International, 99(4), 881-886.

10. Ramaswamy, R. S., \& Darcy, M. D. (2016). Arterial Embolization for the Treatment of Renal Masses and Traumatic Renal Injuries. Techniques in Vascular \& Interventional Radiology, 19(3), 203-210.

11.Jaganjac, S., Schefe, L., Avdagić, E., Spahović, H., \& Hiros, M. (2014). Preoperative kidney tumor embolization as procedure for therapy of advanced kidney cancer. Acta Informatica Medica: AIM: Journal of the Society for Medical Informatics of Bosnia \& Herzegovina: Časopis Društva Za Medicinsku Informatiku BiH, 22(5), 302-305.

12. Buijs, M., Kamel, I. R., Vossen, J. A., Georgiades, C. S., 
Hong, K., \& Geschwind, J.-F. H. (2007). Assessment of metastatic breast cancer response to chemoembolization with contrast agent enhanced and diffusion-weighted MR imaging. Journal of Vascular and Interventional Radiology: JVIR, 18(8), 957-963.

13.Lee, M. S., Kim, M. D., Jung, D. C., Lee, M., Won, J. Y., Park, S. I., ... Lee, K.-H. (2013). Apparent diffusion coefficient of uterine leiomyoma as a predictor of the potential response to uterine artery embolization. Journal of Vascular and Interventional Radiology: JVIR, 24(9), 1361-1365.

14. Noda, Y., Kanematsu, M., Goshima, S., Kondo, H., Watanabe, H., Kawada, H., ... Bae, K. T. (2015). Prediction of early response to uterine artery embolization in fibroids: Value of MR signal intensity ratio. Magnetic Resonance Imaging, 33(1), 51-55.

15. Vandecaveye, V., Michielsen, K., De Keyzer, F., Laleman, W., Komuta, M., Op de beeck, K., ... Maleux, G. (2014). Chemoembolization for hepatocellular carcinoma: 1-month response determined with apparent diffusion coefficient is an independent predictor of outcome. Radiology, 270(3), 747-757.

16. Jones, D.K. (2010). Diffusion MRI: Theory, Methods, and Applications. Oxford University Press USA, P. 132.

17.Zhong, Y., Wang, H., Shen, Y., Guo, A., Wang, J., Kang, S., ... Ye, H. (2017). Diffusion-weighted imaging versus contrast-enhanced MR imaging for the differentiation of renal oncocytomas and chromophobe renal cell carcinomas. European Radiology, 1-10.
Öztürk, M., Ekinci, A., Elbir, Ş. F., Okur, A., Doğan, S., \& Karahan, Ö. I. (2017). Usefulness of Apparent Diffusion Coefficient of Diffusion-Weighted Imaging for Differential Diagnosis of Primary Solid and Cystic Renal Masses. Polish Journal of Radiology, 82, 209-215.

19. Mytsyk, Y., Borys, Y., Komnatska, I., Dutka, I., \& Shatynska-Mytsyk, I. (2014). Value of the diffusionweighted MRI in the differential diagnostics of malignant and benign kidney neoplasms - our clinical experience. Polish Journal of Radiology / Polish Medical Society of Radiology, 79, 290-295.

20.Mytsyk, Y., Dutka, I., Borys, Y., Komnatska, I., Shatynska-Mytsyk, I., Farooqi, A. A., ... Kruzliak, P. (2017). Renal cell carcinoma: applicability of the apparent coefficient of the diffusion-weighted estimated by MRI for improving their differential diagnosis, histologic subtyping, and differentiation grade. International Urology and Nephrology, 49(2), 215-224.

Received: 13-Jun. - 2017

Accepted: 11-Dec. - 2017

18. 